\title{
Trend Change Study of Climate Variables in Xin'anjiang-Fuchunjiang Watershed, China
}

\author{
Muhammad Zaman, ${ }^{1}$ Guohua Fang, ${ }^{1}$ Kashif Mehmood, ${ }^{2}$ and Muhammad Saifullah ${ }^{3}$ \\ ${ }^{1}$ College of Water Conservancy and Hydropower Engineering, Hohai University, Nanjing 210098, China \\ ${ }^{2}$ Faculty of Agricultural Engineering, University of Agriculture, Faisalabad, Pakistan \\ ${ }^{3}$ College of Hydrology and Water Resources, Hohai University, Nanjing 210098, China
}

Correspondence should be addressed to Muhammad Zaman; mzimni85@gmail.com

Received 18 April 2015; Revised 11 June 2015; Accepted 2 August 2015

Academic Editor: Jorge E. Gonzalez

Copyright (C) 2015 Muhammad Zaman et al. This is an open access article distributed under the Creative Commons Attribution License, which permits unrestricted use, distribution, and reproduction in any medium, provided the original work is properly cited.

\begin{abstract}
This study emphasizes the precipitation and the maximum and minimum temperature trend and presents the results of study in temporal and spatial scales, after performing statistical analysis of the Xin'anjiang-Fuchunjiang watershed. Statistical Mann Kendall and Theil Sen techniques were used to determine the trend and its magnitude, respectively, and for determining the start and abrupt change in the trend, Sequential Mann Kendall test has been performed. Furthermore, statistical tests were performed to determine the overall trend in the area at a regional basis. For the removal of the serial effect of the data, prewhitening technique is applied. In this study, statistical tests were performed at 1901-2013 precipitation and temperature series and then after detection of the change year precipitation data were divided into two different scenarios of 1901-1960 period and 1961-2013 period. The results showed that precipitation trend is insignificant while maximum and minimum temperature have increased during 1901-2013 period except for some stations of autumn and summer seasons.
\end{abstract}

\section{Introduction}

Temperature and precipitation have a significance effect on our environment, as water resources are affected by both the precipitation and the air temperature in the form of evapotranspiration. Shortage of precipitation can be responsible for droughts while its excess can cause flooding. Change in water availability can also affect many human activities, such as municipal and industrial water supply to agriculture, power generation, and fisheries [1]. Water is important for life so it is extremely important to know how climate change affects water resources, which is an important issue while planning for the future water supply [2]. Similarly too high temperature is not good for life. Temperature change is a consequence of climate change, which is responsible for significant change in weather patterns over decades to millions of years. Assessment group \#1 of IPCC5 (Intergovernmental Panel of Climate Change) mentioned an increase of 0.3 to $3^{\circ} \mathrm{C}$ in temperature magnitude up to the year 2100 and it will cause change in precipitation and temperature patterns, which consequently will affect regional and global water resources [3, 4]. Hence the spatial distribution of precipitation and temperature is an important issue in the climate-change studies.

Variability of climate change is not the same, and its impact varies over the entire globe from region to region [5]. Spatial and temporal distribution of precipitation is very important for hydrology and water resources application [6]. At mid and high latitudes of the northern hemisphere $0.5-1 \%$ increase in precipitation per decade has been noticed while $7-12 \%$ and $2 \%$ increases in the annual average precipitation trend have been found at $30-85^{\circ} \mathrm{N}$ and $0-55^{\circ} \mathrm{S}$ regions in 20th century, respectively [7]. A working group of IPCC has also observed variations in precipitation trend spatially, such that the eastern parts of southern and northern America and some parts of Europe and central and northern Asia exhibit an increasing trend in precipitation while Sahel, the Mediterranean, and some parts of southern Asia and Africa showed a decreasing precipitation trend during 1900-2005 [8]. Tropical areas exhibit an insignificant change in precipitate trend while mid latitude of the northern hemisphere 
$\left(30-60^{\circ} \mathrm{N}\right)$ experienced a significant increase in precipitation trends in long term data (1901-2008) stated by IPCC 2013 [9]. Global warming affects the precipitation patterns ultimately affecting the water resources and hydrology [10]. Ground water is also affected due to the change in climate [11]. Qin Dahe worked on the climate change and noticed that in the last 100 years global warming has caused an increase of 0.6 to $0.8^{\circ} \mathrm{C}$ year in mean annual temperature in China [12]. It is studied that climate change is affecting water resources of China and streamflow is increasing in the most parts of the watershed in the area [13]. Therefore, it is very important to study changes in water patterns due to the climate change in the medium sized watershed (Xin'anjiang-Fuchunjiang) for the improvement of water resource design and application and management techniques that are associated with climate change.

Many researchers have conducted a large number of studies around the globe for detecting the climate change and performing trend analysis. He and Zhang studied the climatechange trend in China along Lancer River during 19602000, using the data from 19 stations [14]. Several statistical and dynamical approaches have been developed for trend detection. Usually, parametric and nonparametric methods are in use while it is observed that the parametric method is less reliable than nonparametric method [15]. Scientists have found that among the nonparametric approaches Mann Kendall (MK) trend analysis approach is getting significant importance nowadays for the detection of climate-change trends [16, 17]. Usually, Mann Kendall and Theil Sen's nonparametric approaches are used for trend detection and its magnitude, respectively $[18,19]$. Numerous scientists have applied these approaches for trend detection. Nalley et al. applied Mann Kendall technique in Canada for determining air temperature trend for the time period of 1967-2006 [20]. Gu et al. used Mann Kendall approach for detection of runoff trend of major rivers of China [13]. Karaburun et al. used Mann Kendall and Sen's method in Istanbul for trend detection of temperature during the period of 1975 to 2006 [21]. Ceppi et al. used temperature data from 1959 to 2008 in Switzerland to determine the trend. Results revealed an $0.35^{\circ} \mathrm{C} /$ decade increase in the temperature [22]. Fan and Wang studied the change in temperature trend in Shanxi province in China, and they found an increase in the temperature trend [23]. Tao et al. studied trend change in streamflow using the past 50 years data belonging to Tarim River basin. They found an increase in temperature, relative humidity, precipitation, and actual vapour pressure trends but decrease in wind speed, sunshine hours, and potential evapotranspiration trends [24]. Jiang et al. examined wind speed trend during 1956-2004 in China. They used two datasets and found that the trend is decreasing in the area [25]. Singh et al. used Mann Kendall approach in order to determine the trend of precipitation and relative humidity in India. Results showed that there is an increasing trend in relative humidity in most parts of the river basin [26]. EINesr et al. examined 29 stations data to determine the temperature trend in Saudi Arabia and concluded that except for the winter months there is increase in trend for maximum, minimum, and average temperatures in the area [27].
Determination of beginning, change, and abrupt changes in the trend in long time data series is also important in climate studies. Sequential Mann Kendall technique is becoming popular for the determination of start of trend and abrupt change in trends [28-30].

This study was conducted to find the change in precipitation and minimum and maximum temperature trends in Xin'anjiang-Fuchunjiang watershed for long time data series (1901-2013). MK statistical technique was applied for trend detection, and for its magnitude, Theil Sen technique was used. Also for the determination of start of trend and abrupt change in it, use has been made of Sequential Mann Kendall method. This study will be beneficial for the estimation and planning of water resources tasks in the area.

\section{Materials and Methods}

2.1. Study Area and Data Collection. The study area is Xin'anjiang-Fuchunjiang watershed (Figure 1), located between latitude $28^{\circ} 15^{\prime}-30^{\circ} 15^{\prime} \mathrm{N}$ and longitude $117^{\circ} 45^{\prime}-120^{\circ} 15^{\prime}$, with an area of approximately $35620.2 \mathrm{~km}^{2}$. The study area is located in east China near Jiande city in the northwest of Zhejiang province. The study area has a famous 105 meters high and 466.5 meters long Xin'anjiang Dam with 22 billion $\mathrm{m}^{3}$ storage capacity and a maximum flood discharging capability of $14,000 \mathrm{~m}^{3} / \mathrm{s}$ and forms a large reservoir (thousand-island lake) with 1,078 islands. This reservoir links Hangzhou, the capital of Zhejiang province, with the famous Mount Huangshan in the neighboring Anhui Province. This watershed includes the Xin'anjiang $\left(119^{\circ} 13^{\prime} 31\right.$ longitude and $29^{\circ} 28^{\prime} 38.16$ latitude) hydropower station located at the Qiantang River, with a total installed capacity of $845,000 \mathrm{kw}$ and annual output of 1.86 billion kwh. This and Fuchunjiang $\left(119^{\circ} 39^{\prime} 10.72\right.$ Longitude and $29^{\circ} 42^{\prime} 37.31$ Latitude) hydropower station are shown in Figure 1. Fuchunjiang Hydropower Station is approximately $60 \mathrm{~km}$ downstream of Xin'anjiang hydropower station and more than $110 \mathrm{~km}$ upstream of Hangzhou City. Fuchunjiang reservoir is of daily regulation type, with a 920 million $\mathrm{m}^{3}$ total storage capacity. The total installed power generation capacity is $297.2 \mathrm{MW}$ with a 923 million kWh annual energy output. The study area has approximately $1708 \mathrm{~km}^{2}$ of irrigated farmland used to grow rice, wheat, soybean, corn, and potato, and some cash crops such as sugarcane, tea, cotton, and medicinal herbs are common. These hydropower stations and irrigated land increase the importance of this study, because change in precipitation or temperature trends affects the water resources in the area, ultimately impacting the water demand.

As it is difficult to get long term data for the empirical analysis of temperature and precipitation trends, $0.5 * 0.5^{\circ}$, high resolution gridded data were obtained from the Climate Research Unit (http://badc.nerc.ac.uk/home/index.html). These data have been generated in the CRUTS2.1 from station observations dataset [31] and have been used in many studies [32-34]. Temperature and precipitation data were categorized into seasonal (winter, spring, summer, and autumn) and annual data series as given in Table 1 . 


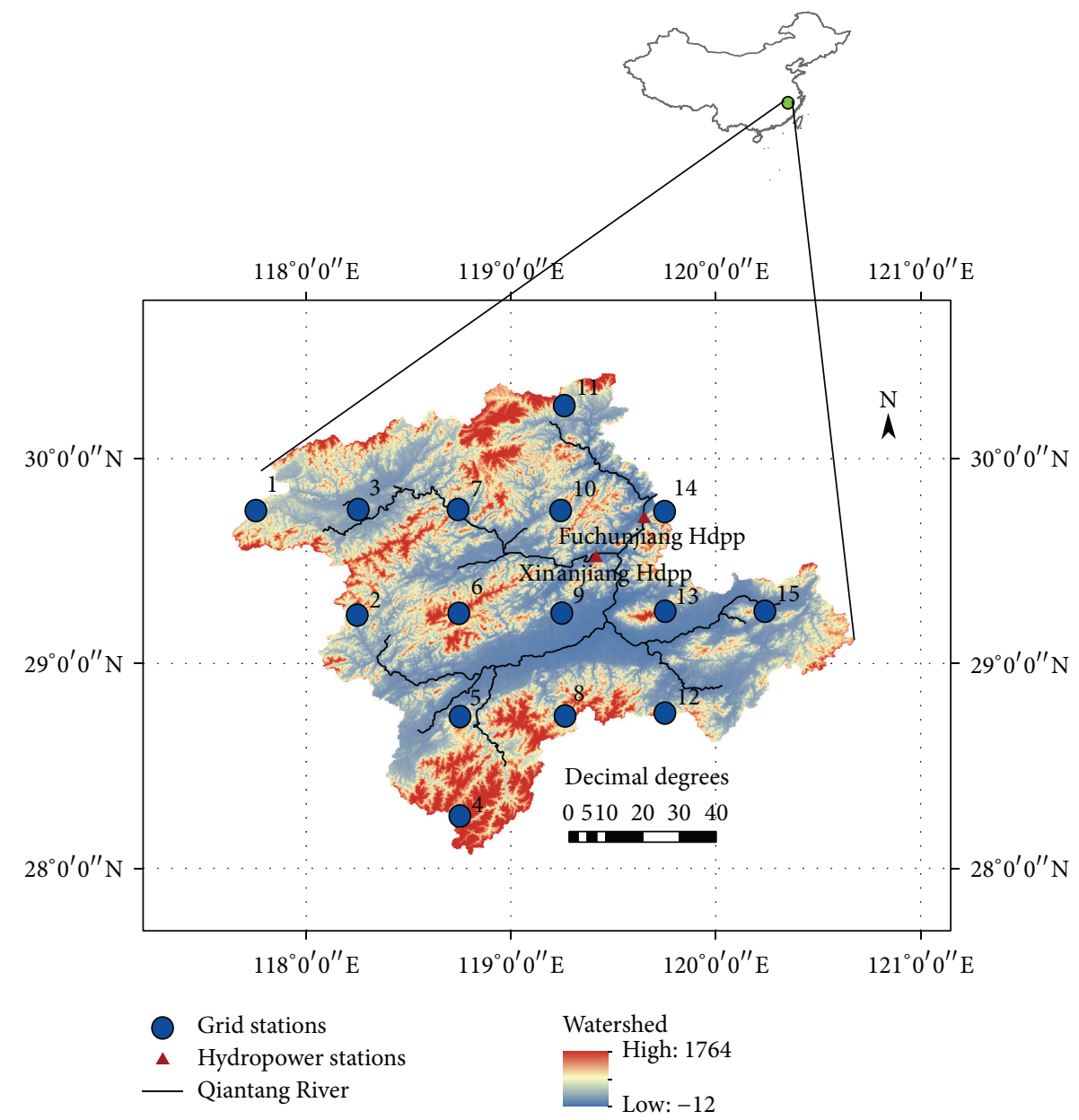

FIGURE 1: Spatial distribution of grid points in Xin'anjiang-Fuchunjiang watershed map.

TABLE 1: Different seasons for analysis.

\begin{tabular}{lcc}
\hline Sr. number & Season & Month \\
\hline 1 & Annually & Jan-Dec \\
4 & Winter & Dec-Feb \\
5 & Spring & March-May \\
6 & Summer & June-August \\
7 & Autumn & Sep-Nov \\
\hline
\end{tabular}

2.2. Material and Methods. Data from 1901 to 2013 related to 15 grid points/station were collected and categorized into annual and seasonal time series as given in Table 1. In order to detect the homogeneity of data, autocorrelation approach was applied on the data $[30,31]$ and then Mann Kendall nonparametric test and Sen's slope estimation techniques were used to determine temperature and precipitation trends and their magnitude, respectively. Mann Kendall Sequential technique was applied in order to detect the abrupt change and beginning of trend in data.

2.2.1. Serial Correlation Effect. Von Storch and Navarra proposed a prewhitening technique to remove serial correlation effect from the data series [35]. The following proposed steps were followed during this research work with the sample data $\left(x_{1}, x_{2}, \ldots, x_{n}\right)$.

(i) Salas et al. proposed lag-1 serial coefficient $r_{1}$ for the determination of serial effect in data [36]. Most of researchers used this approach in order to determine the serial effect [37]. It is calculated as given in

$$
\begin{aligned}
& r_{1}=\frac{(1 /(n-1)) \sum_{i=1}^{n-1}\left(x_{i}-E\left(x_{i}\right)\right)\left(x_{i+1}-E\left(x_{i}\right)\right)}{(1 / n) \sum_{i=1}^{n} *\left(x_{i}-E\left(x_{i}\right)\right)^{2}}, \\
& E\left(x_{i}\right)=\frac{1}{n} \sum_{i=1}^{n} x_{i}
\end{aligned}
$$

where $n$ is the number of observations and $E\left(x_{i}\right)$ is the mean of data.

(ii) Equation (4) is used to test the time series

$$
\frac{-1-1.645 \sqrt{(n-2)}}{n-1} \leq r_{1} \leq \frac{-1+1.645 \sqrt{(n-2)}}{n-1} .
$$

Data are correlated if $r_{1}$ is not within the above interval; otherwise they are independent. Prewhitening of real data 
is needed if they are serially correlated as $\left(x_{2}-r_{1} x_{1}, x_{3}-\right.$ $\left.r_{1} x_{2}, \ldots, x_{n}-r_{1} x_{n-1}\right)$.

2.2.2. Mann Kendall (MK) Trend Test. Tests for the detection of trend significance in data are categorized into the parametric and nonparametric approaches. Data should be distributed and be independent for the parametric approach while only independent data are the requirement of nonparametric approach. Here Mann Kendall nonparametric technique was used for the detection of trend variability while its magnitude and slope estimation were found using Sen's slope method. These two approaches are mainly used to analyze the chemistry of the climatology data. Statistics of Mann Kendall are based upon the sign of the difference, rather than random variable values.

The Mann Kendall test statistic " $S$ " is calculated by

$$
\sum_{i=1}^{n-1} \sum_{j=i+1}^{n} \operatorname{sgn}\left(x_{j}-x_{i}\right)
$$

In (4) $x_{i}$ and $x_{j}$ are the annual values of $i$ and $j$ years, respectively, where $j>i$ and $n$ is the number of data points, and significantly $\left(x_{j}-x_{k}\right)$ is the sign function given below

$$
\operatorname{sgn}\left(x_{j}-x_{i}\right)= \begin{cases}+1, & \text { if }\left(x_{j}-x_{i}\right)>0 \\ 0, & \text { if }\left(x_{j}-x_{i}\right)=0 \\ -1, & \text { if }\left(x_{j}-x_{i}\right)<0 .\end{cases}
$$

The variance is calculated as

$$
V(S)=\frac{n(n-1)(2 n+5)-\sum_{k=1}^{m} t_{k}\left(t_{k}-1\right)\left(2 t_{k}+5\right)}{18}
$$

In (6), $n$ and $m$ are the number of data points and tied groups, respectively, where $t_{k}$ is the number of ties of extent $k$. Sample data in a tied group have the same value; if the sample size is $n>10$, then test statistics $Z_{s}$ is computed using

$$
Z_{s}= \begin{cases}\frac{S-1}{\sqrt{V(S)}} & \text { if } S>0 \\ 0 & \text { if } S=0 \\ \frac{S+1}{\sqrt{V(S)}} & \text { if } S<0 .\end{cases}
$$

Increase and decrease in the trend could be judged easily from $Z_{s}$ value. A positive value means the increasing trend while its negative value indicates a decreasing trend, where $S$ represents the standard deviation. If $Z_{1-\alpha / 2}$ is greater than $Z_{s}$ then $H_{0}=$ rejected, which means the trend is significant, where $Z_{1-\alpha / 2}$ value is given in standard normal cumulative distribution table; Mann Kendall nonparametric approach is used to determine the significance of a trend at significant level $\alpha=0.001$ (or 99.99\% confidence interval), $\alpha=0.01$ (or $99 \%$ confidence interval), $\alpha=0.05$ (or 95\% confidence interval), and $\alpha=0.1$ ( $90 \%$ confidence interval) of time series data. If value of $\left|Z_{s}\right|>1.65$ or $\left|Z_{s}\right|>1.96$ then the trend is significant at $10 \%$ and $5 \%$ significance levels, respectively, while if $\left|Z_{s}\right|>2.57$ or $\left|Z_{s}\right|>3.2$ then the trend is significant at $1 \%$ and $0.1 \%$; significance level and the null hypothesis are rejected.

2.2.3. Theil Sen Approach (TSA). Sen [19] developed a nonparametric approach to calculate the trend magnitude and its slope. For the calculation of the slope, $N$ pairs equally spaced time data series, sorted in the ascending order, and the following formula is used:

$$
Q_{k}=\frac{\left(x_{j}-x_{i}\right)}{j-i} \text { for } k=1, \ldots, N .
$$

In (8), $x_{i}$ and $x_{j}$ are data values at time series $i$ and $j$, respectively, where $j>i, N=n(n-1) / 2$, and $n$ is the total number of data points.

$N$ values of $Q_{k}$ are ranked in ascending order and $Q$ median $\left(Q_{\text {med }}\right)$ is obtained using

$$
Q_{\text {med }}= \begin{cases}Q_{(N+1) / 2} & \text { if } N \text { is odd } \\ \frac{Q_{N / 2}+Q_{(N+2) / 2}}{2} & \text { if } N \text { is even. }\end{cases}
$$

While the magnitude of $Q_{\text {med }}$ represents slope steepness, the positive or negative sign shows the increasing or decreasing trend direction.

2.2.4. Identification of Precipitation Shifts. (i) Many researchers have used Sequential Mann Kendall (SQMK) method to determine the start of trend and abrupt change in it $[30,38$, 39]. SQMK is a ranked based test having the following steps.

(ii) At each comparison, the $y_{i}>y_{j}$ cases are counted and denoted by $n_{i}$; where $y_{i}=(1,2,3, \ldots, i)$ and $y_{j}=(2,3,4, \ldots$, $i-1)$ are the sequential values of data series. The test statistics is given in

$$
t_{i}=\sum_{j=1}^{i} n_{j}
$$

(iii) The mean of test statistics is given as

$$
E\left(t_{i}\right)=\frac{i(i-1)}{4} .
$$

Moreover, the variance is given in

$$
\operatorname{Var}\left(t_{i}\right)=\frac{i(i-1)(2 i+5)}{72} .
$$

(iv) The SQMK value is calculated using

$$
u\left(t_{i}\right)=\frac{t_{i-E(t)}}{\sqrt{\operatorname{Var}\left(t_{i}\right)}} .
$$

Original time series is used $\left(x_{1}, x_{2}, x_{3}, \ldots, x_{n}\right)$ for forward $u\left(t_{i}\right)$ while time series is resorted and reversed for getting the backward statistics $u^{\prime}\left(t_{i}\right)$. Change point detection is acceptable if both curves match below a significance level; otherwise it is rejected. 


\section{Results and Discussions}

3.1. Overall Data Series (1901-2013). Nonparametric Mann Kendall and TSA techniques were applied to precipitation and maximum/minimum temperature data series from 1901 to 2013, and the results obtained are presented in Figures 2, 3, and 4 .

\subsubsection{Precipitation}

(a) Annual Precipitation. Results revealed an insignificant trend for the annual precipitation data series. Most grid points exhibit an insignificant trend as shown in Figure 2. It is salient that most stations located at the west side of watershed have an insignificant trend with 0.07 to $0.20 \mathrm{~mm} /$ year increase in precipitation, whereas grid points located at the east side show an insignificant decreasing trend at -0.18 to $0 \mathrm{~mm} /$ year.

(b) Seasonal Precipitation. All grid points of the watershed exhibit an insignificant trend with a positive change of 0.06$0.46 \mathrm{~mm} /$ year for the winter data series as shown in Figure 2 . Precipitation data series of spring, summer, and autumn exhibit insignificant trends as shown in Figure 2 during 19012013.

\subsubsection{Maximum Temperature (TMax)}

(a) Annual. Annual data series of maximum temperature over the watershed during 1901-2013 exhibit significant increasing trend as shown in Figure 3. Annual temperatures have increased at a rate of $0.21-0.28^{\circ} \mathrm{C} /$ decade.

(b) Seasonal. All seasonal data series have shown a significant increasing trend for maximum temperature as shown in Figure 3. Winter season shows a significant increasing trend at a rate of up to $0.25^{\circ} \mathrm{C} /$ decade at most grid points, spring data series have shown an increasing trend at the rate of $0.24-0.29^{\circ} \mathrm{C} /$ decade, and summer data series have shown an increasing trend at a rate of up to $0.19-0.24^{\circ} \mathrm{C} /$ decade. An increasing trend for the autumn data series has observed an increase of $0.16-0.25^{\circ} \mathrm{C} /$ decade.

3.1.3. Minimum Temperature (TMin). Statistical results of annual and seasonal data series of TMin are presented in Figure 4.

(a) Annual. Annual data series for minimum temperature has shown an increasing trend at all grid points at a rate up to $0.17^{\circ} \mathrm{C} /$ decade as shown in Figure 4 .

(b) Seasonal. Minimum temperature of 1901-2013 seasonal data series exhibits an increasing trend over all the watershed as shown in Figure 4.

Results revealed that the winter season has a significant increasing trend at a rate of up to $0.11-0.22^{\circ} \mathrm{C} /$ decade during 1901-2013 as shown in Figure 4. 80\% of stations at spring season exhibit an increasing trend up to $0.18^{\circ} \mathrm{C} /$ decade. It can be seen from Figure 4 that up to $50 \%$ of stations in the watershed have a significant increasing trend with a trend magnitude of up to $0.15^{\circ} \mathrm{C} /$ decade. Results revealed that $75 \%$ of stations of the autumn data series have significantly increasing trends with $0.06-0.16^{\circ} \mathrm{C} /$ decade increase, as shown in Figure 4.

3.2. Change Point Detection. The Sequential Mann Kendall (SQMK) Technique has been applied on the precipitation and temperature (1901-2013) data series. SQMK results of precipitation obtained are displayed in Table 2 and for annual TMax data series of station number 15 is shown in Figure 5. Results revealed that most stations of the precipitation data series exhibit insignificant positive or negative change around 1960 for annual and seasonal data series. Conversely, trend for maximum and minimum temperature have increased throughout 1901-2013 after 1915 as shown in Figure 5. Due to the said reason, the precipitation data series has been divided into two series for periods 1901-1960 and 1961-2013 for the application and determination of trends and their magnitude using Mann Kendall and Theil Sen's approaches, respectively.

\subsection{Precipitation Data Series}

3.3.1. First Data Series (1901-1960). The results of precipitation during the first data series period (1901-1960) are given in Table 3. A mix of insignificant positive and negative trends in the annual and seasonal data series was detected as given in Table 3. Results revealed that about $20 \%$ of stations have increased precipitation trends at a significant level of $5 \%$ with an increasing rate of $0.34 \mathrm{~mm} /$ year to $0.68 \mathrm{~mm} /$ year, while only one station has a decreasing trend at a rate of $-0.30 \mathrm{~mm} /$ year in the annual data series at a $5 \%$ significance level. Results of the seasonal data series revealed that $26 \%$ of winter data stations have an increased trend of $0.59 \mathrm{~mm} /$ year to $1.02 \mathrm{~mm} /$ year as given in Table 3, at $1 \%$ and $5 \%$ significance level, while all other stations have insignificant trend.

3.3.2. Second Data Series (1961-2013). The statistical results of annual and seasonal precipitation (1961-2013) data series have been obtained and displayed in Table 4 . The results revealed that most stations have shown nonsignificant positive and negative trends. Also the results revealed that winter precipitation time series have insignificant positive trends at most stations within the study area. Analyses of spring have shown insignificant negative trend, while summer and autumn precipitation time series have shown insignificant positive trend at most stations as displayed in Table 4.

3.4. Comparison of Mann Kendall and Sen's Methods. Results of Sen's slope estimator for the annual and seasonal data series related to the temperature and the rainfall for the year consisting of two time periods are given in Table 5. Results obtained show a great similarity between Mann Kendall and Sen's slope methods, as many researchers have already mentioned about this companion and found that there is not much difference in these results $[28,36,37]$. 


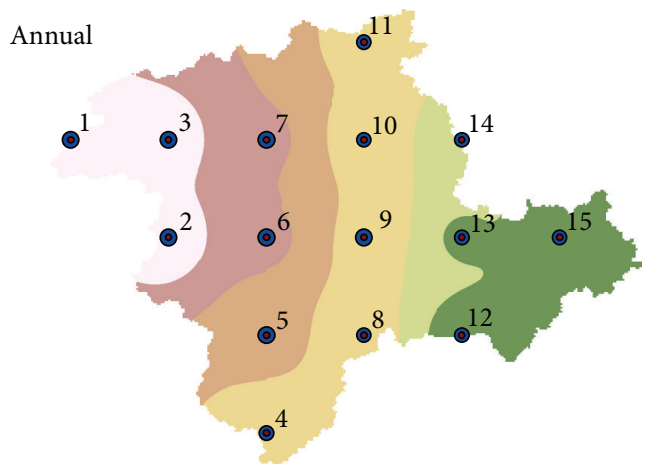

TSA magnitude (mm/year)

$$
\begin{aligned}
& \square-0.18-0.12 \quad \square \quad 0.00-0.07 \\
& \square-0.12-0.05 \quad \square 0.07-0.14 \\
& \square-0.05-0.00 \quad \square \quad 0.14-0.20
\end{aligned}
$$
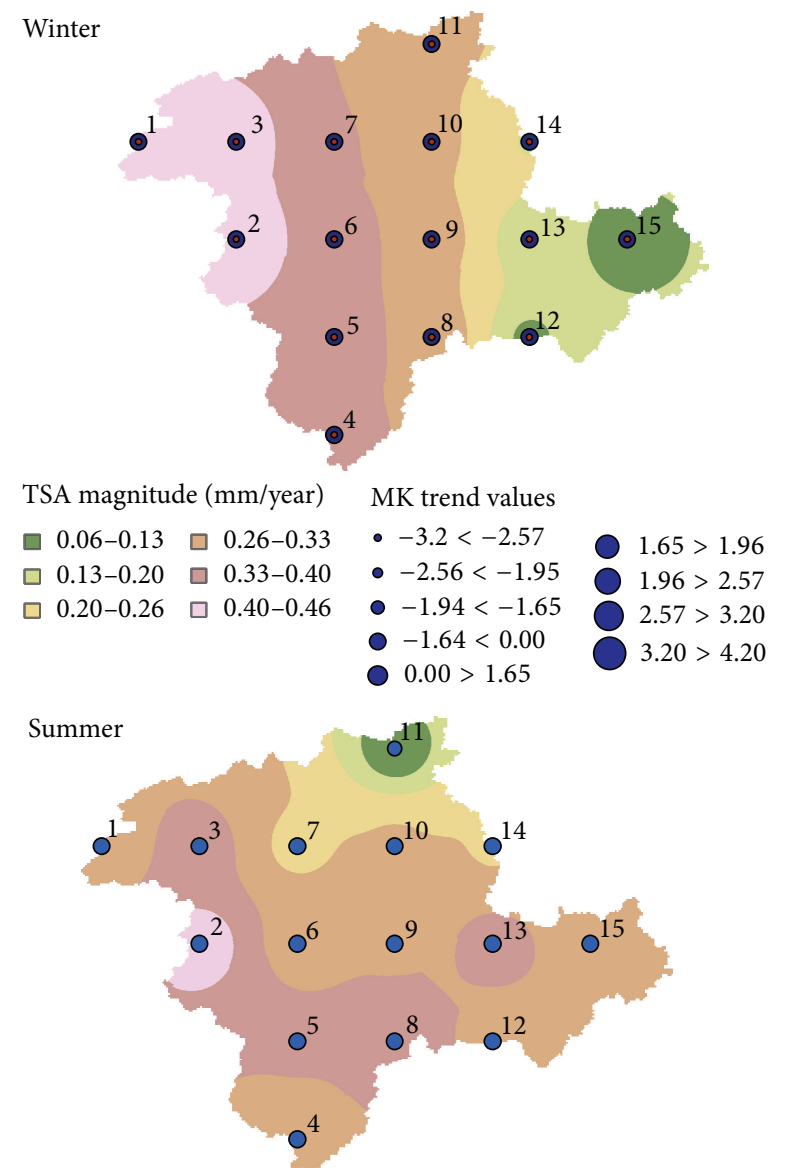

TSA magnitude ( $\mathrm{mm} / \mathrm{year}) \quad$ MK trend values $-0.00-0.03 \square 0.10-0.14 \quad--3.2<-2.5$

$\square 0.03-0.07 \square 0.14-0.18 \quad \bullet-2.56<-1.95$

$\square 0.07-0.10 \quad \square 0.18-0.22 \quad \circ-1.94<-1.65$

○ $-1.64-0.0$

$0.0>1.65$

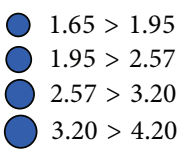

MK trend values

- $-3.2<-2.57$

- $-2.56<-1.96$

- $-1.95<-1.65$

- $-1.64-0.0$

$0.0>1.65$

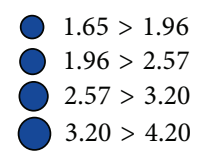

Spring

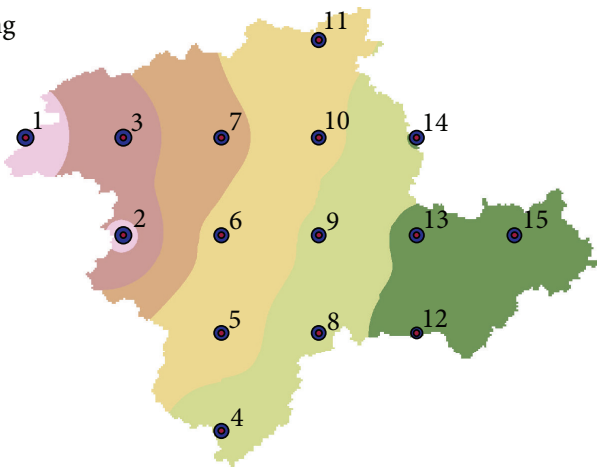

TSA magnitude ( $\mathrm{mm} /$ year) $\quad$ MK trend values

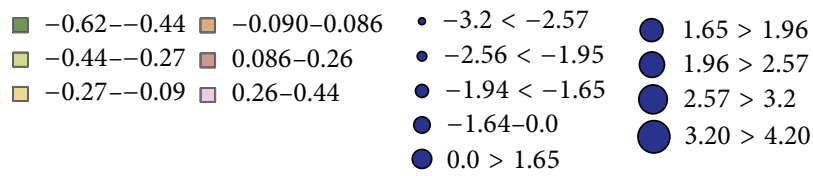

Autumn

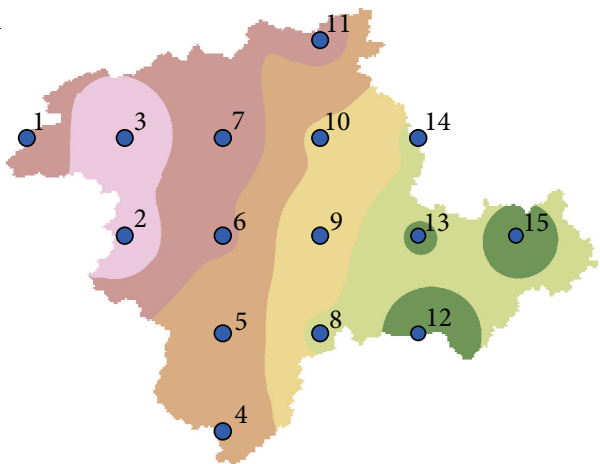

TSA magnitude ( $\mathrm{mm} /$ year)

MK trend values

口 $-0.01-0.04 \square 0.07-0.13 \quad--3.20<-2.57$

$\square-0.04-0.02 \square 0.13-0.20 \quad \bullet-2.56<-1.96$

$\square 0.02-0.07 \square 0.20-0.25 \quad 0-1.95<-1.65$

○ $-1.64-0.0$

$0.00-1.65$

FIGURE 2: Spatial distribution of stations with MK test results and interpolated TSA magnitude (mm/year) of annual and seasonal precipitation data series over the period of 1901-2013. 


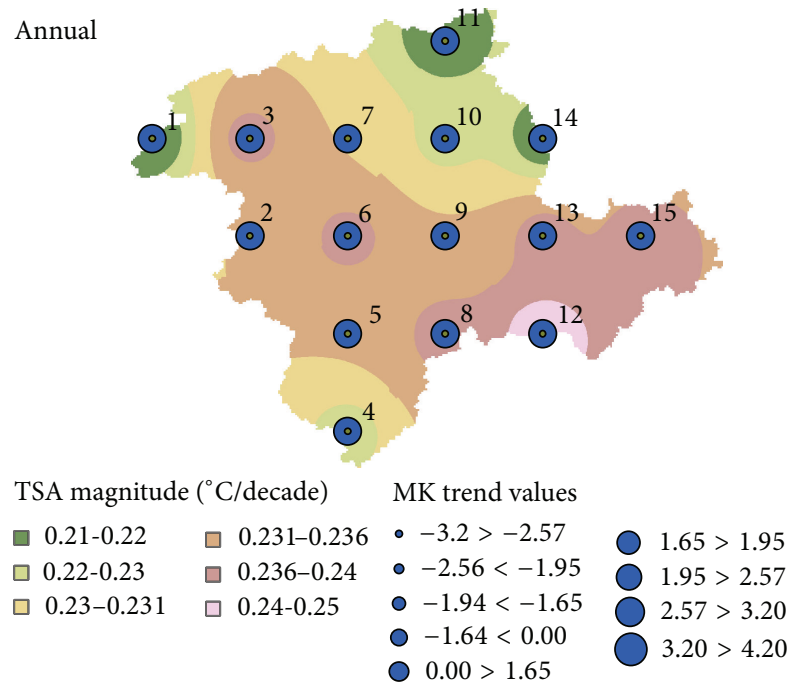

Winter

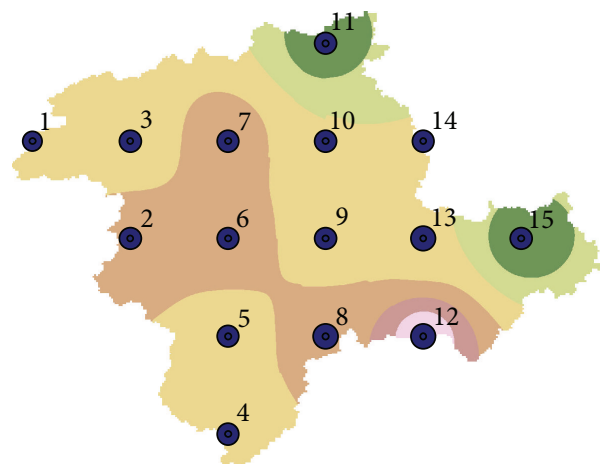

TSA magnitude ( ${ }^{\circ} \mathrm{C} /$ decade $)$

$\square$ 0.21-0.214 $\square 0.224-0.23$

$\square 0.214-0.22 \square 0.23-0.235$

$\square 0.22-0.224 \square 0.235-0.24$

MK trend values

- $-3.2<-2.57$

- $-2.56<-1.95$

- $-1.94<-1.65$

- $-1.64<0.00$

- $0.00<1.65$

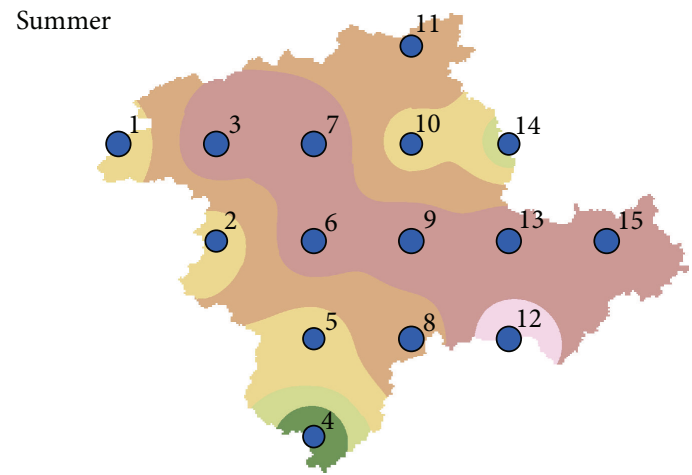

TSA magnitude ( ${ }^{\circ} \mathrm{C} /$ decade)

MK trend values

0.19-0.20

口 $0.22-0.223$

- $-3.2<-2.57$

$\square 0.20-0.21$

ㅁ $0.223-0.232$

$\square 0.21-0.22$

$0.232-0.24$

- $-2.56<-1.95$

- $-1.94<-1.65$

○ $-1.64<0.00$

○ $0.00<1.65$
Spring

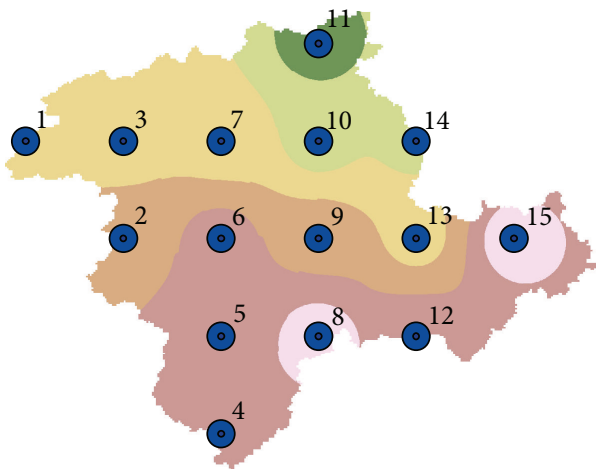

$$
\begin{aligned}
& \text { TSA magnitude }\left({ }^{\circ} \mathrm{C} / \text { decade }\right) \quad \text { MK trend values } \\
& \square \text { 0.24-0.25 } \square 0.27-0.273 \quad--3.2<-2.57 \\
& \square 0.25-0.26 \square 0.273-0.281 \bullet-2.56<-1.95 \\
& \square 0.26-0.27
\end{aligned}
$$

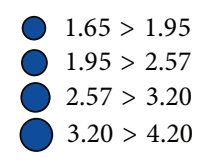

Autumn

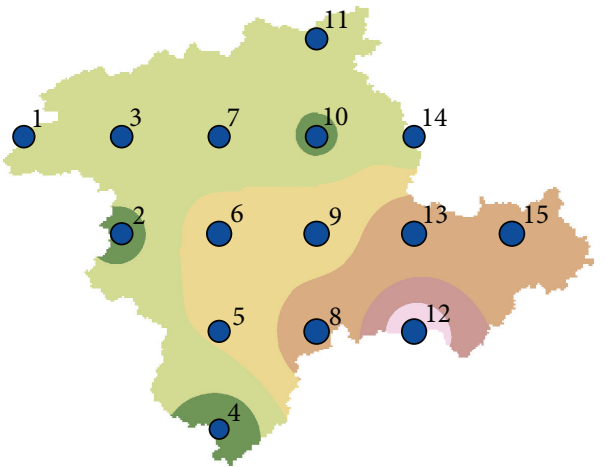

TSA magnitude $\left({ }^{\circ} \mathrm{C} /\right.$ decade $) \quad$ MK trend values

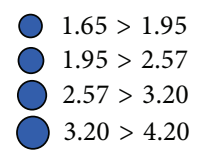

0.16-0.18 0.21-0.22

- $-3.2<-2.57$

- $-2.56<-1.95$

○ $-1.94<-1.65$

- $-1.64<0.00$

$0.01>1.65$

FIGURE 3: Spatial distribution of stations with MK test results and interpolated TSA magnitude ( $\left.{ }^{\circ} \mathrm{C} / \mathrm{decade}\right)$ of annual and seasonal TMax data series over the period of 1901-2013. 

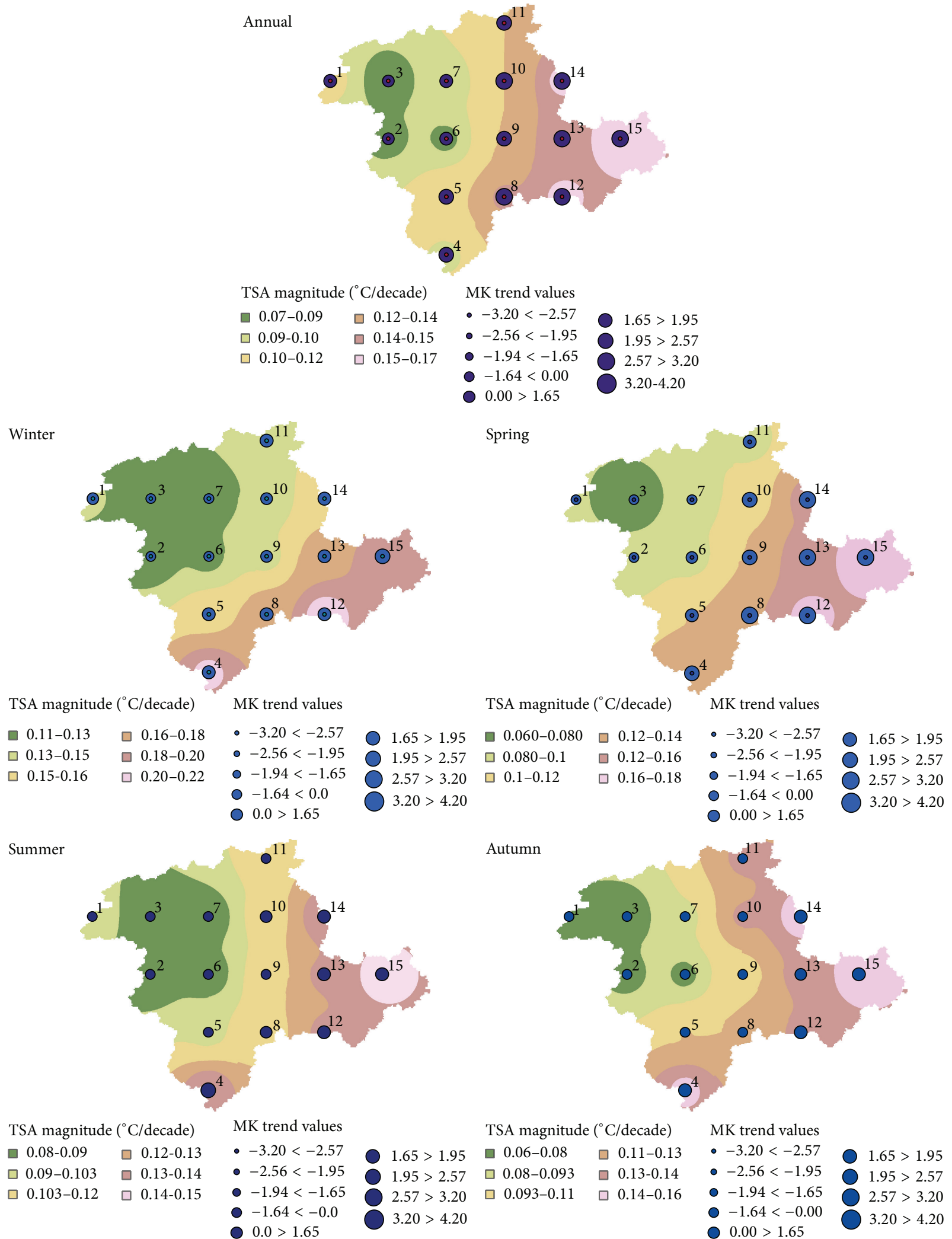

FIGURE 4: Spatial distribution of stations with MK test results and interpolated TSA magnitude $\left({ }^{\circ} \mathrm{C} / \mathrm{decade}\right)$ of annual and seasonal TMin data series over the period of 1901-2013. 
TABLE 2: Change point detection during the period of 1901-2013.

\begin{tabular}{|c|c|c|c|c|c|c|}
\hline \multirow{2}{*}{ Station number } & & \multicolumn{5}{|c|}{ Precipitation } \\
\hline & & Annual & Winter & Spring & Summer & Autumn \\
\hline 1 & Change point & -1960 & -1954 & -1960 & -1961 & +1959 \\
\hline 2 & Change point & -1958 & -1955 & -1955 & * & * \\
\hline 3 & Change point & -1960 & -1960 & -1958 & -1958 & * \\
\hline 4 & Change point & -1963 & * & -1960 & * & +1955 \\
\hline 5 & Change point & -1961 & * & -1958 & * & * \\
\hline 6 & Change point & -1958 & * & -1965 & * & $*$ \\
\hline 7 & Change point & -1959 & -1949 & -1964 & * & * \\
\hline 8 & Change point & -1963 & $*$ & - & * & +1959 \\
\hline 9 & Change point & -1968 & * & - & * & +1966 \\
\hline 10 & Change point & -1969 & * & - & * & +1951 \\
\hline 11 & Change point & -1960 & * & -1959 & * & $*$ \\
\hline 12 & Change point & * & * & - & * & * \\
\hline 13 & Change point & $*$ & $*$ & - & $*$ & $*$ \\
\hline 14 & Change point & $*$ & * & - & * & +1963 \\
\hline 15 & Change point & * & $*$ & * & * & * \\
\hline
\end{tabular}

* shows no change (meaning positive remains positive and negative remains negative) whereas - shows negative and + shows positive change in precipitation trend.

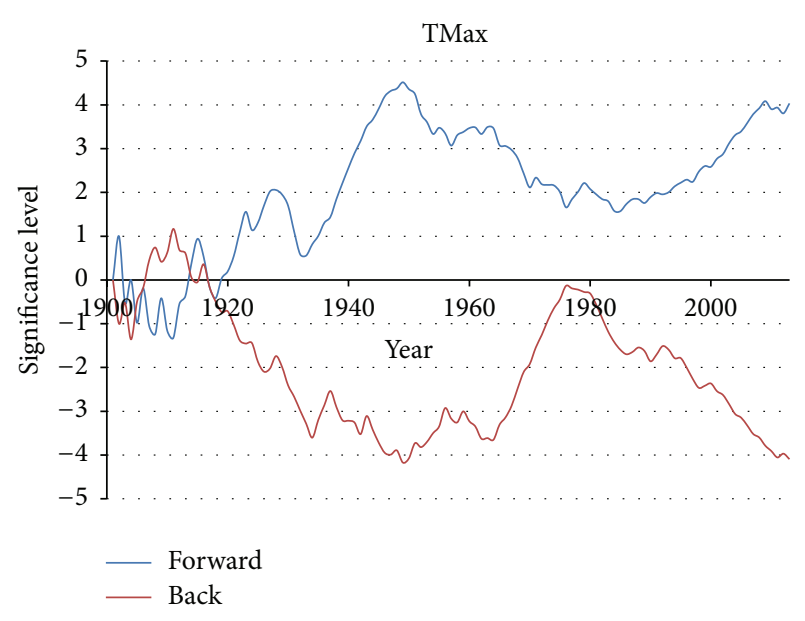

FIGURE 5: Change point detection of TMax during 1901-2013.

3.5. Overall Watershed Trend. To ascertain an idea about the overall precipitation and temperature trend in the watershed, statistical tests have been applied using the average of seasonal and annual data of all 15 grid stations. The results obtained after applying Mann Kendall and TSA statistical tests are displayed in Table 6. Results showed that none of the seasonal and annual precipitation data have a significant trend at $1 \%$ significance level for both time series. Results of TMax data showed a significant trend at 5\% and $1 \%$ significance levels for the time series of annual and seasonal data with TSA magnitude between 0.014 and $0.033^{\circ} \mathrm{C} /$ year/ season. The annual and seasonal time series of TMin show a significant trend for most of the data series except autumn data at $5 \%$ and $1 \%$ significance levels. The TSA magnitude of the significance trend value varies between 0.010 and $0.022^{\circ} \mathrm{C} /$ year/season for the study area.

\section{Discussion}

This study investigated the change in seasonal and annual precipitation, TMax, and TMin in the Xin'anjiang-Fuchunjiang watershed over a 113-year period. Precipitation trends were also analyzed for the 1901-1960 and 1961-2013 data series.

The results of study follow the same statistical trends of precipitation, both positive (annual, winter, summer, and autumn) and negative (spring), reported by Song et al. [40] for the northwest part of Zhejiang in eastern China. Findings were also consistent with the studies by Tian et al. [41] and Wang and Zhou [42] on the northwest part of Zhejiang, where a mix positive and negative trends of precipitation for annual and seasonal data was found. Our temperature (TMax and TMin) results were consistent with those found by Zhao et al. [43], Dong et al. [44], and Tang et al. [45], with significant positive trend in temperature during the 20th century. The mostly grid stations at high elevation exhibit higher temperature trends and follow the same results found by Dong et al. [44].

These positive trends can also affect the water resources of the area. Runoff in the study area did not significantly increase (increase insignificantly) due to positive trends of precipitation and temperature, and there was no shortage of water demands for agriculture, hydropower, and domestic use [46]. This increasing water flow can cause flooding in the area, as stated by Piao et al. during 20th century [46].

\section{Conclusion}

The present study examined the precipitation, TMax, and TMin data for the period 1901-2013 for trend prediction in Xin'anjiang-Fuchunjiang watershed. Nonparametric Mann Kendall and Theil Sen's approaches have been used for trend 
TABLE 3: Mann Kendall and TSA results of precipitation during the period of 1901-1960.

\begin{tabular}{|c|c|c|c|c|c|c|}
\hline Stations & & Annual & Winter & Spring & Summer & Autumn \\
\hline \multirow{2}{*}{1} & $Z$ & 2.30 & 3.33 & 2.35 & 0.62 & -0.01 \\
\hline & Q & 0.65 & 1.02 & 1.46 & 0.35 & 0.00 \\
\hline \multirow{2}{*}{2} & $Z$ & 1.95 & 2.51 & 1.70 & 1.12 & 0.62 \\
\hline & Q & 0.62 & 0.98 & 1.08 & 0.43 & 0.16 \\
\hline \multirow{2}{*}{3} & $Z$ & 2.22 & 2.89 & 1.66 & 0.95 & 0.64 \\
\hline & Q & 0.54 & 0.95 & 0.97 & 0.41 & 0.18 \\
\hline \multirow{2}{*}{4} & $Z$ & 0.20 & 1.58 & 0.13 & 0.49 & -0.15 \\
\hline & Q & 0.03 & 0.59 & 0.09 & 0.22 & -0.04 \\
\hline \multirow{2}{*}{5} & $Z$ & 0.97 & 1.61 & 0.22 & 0.68 & 0.00 \\
\hline & Q & 0.21 & 0.71 & 0.16 & 0.27 & 0.00 \\
\hline \multirow{2}{*}{6} & $Z$ & 1.58 & 1.79 & 0.76 & 0.47 & 0.17 \\
\hline & Q & 0.34 & 0.74 & 0.36 & 0.19 & 0.06 \\
\hline \multirow{2}{*}{7} & $Z$ & 1.67 & 2.15 & 0.96 & 0.38 & 0.39 \\
\hline & Q & 0.34 & 0.70 & 0.41 & 0.17 & 0.11 \\
\hline \multirow{2}{*}{8} & $Z$ & 0.10 & 1.09 & -0.59 & 0.48 & -0.46 \\
\hline & Q & 0.02 & 0.44 & -0.23 & 0.17 & -0.13 \\
\hline \multirow{2}{*}{9} & $Z$ & 0.64 & 1.38 & -0.05 & 0.37 & -0.19 \\
\hline & Q & 0.10 & 0.50 & -0.01 & 0.11 & -0.06 \\
\hline \multirow{2}{*}{10} & $Z$ & 0.68 & 1.54 & -0.05 & 0.20 & -0.10 \\
\hline & Q & 0.11 & 0.52 & -0.01 & 0.05 & -0.02 \\
\hline \multirow{2}{*}{11} & $Z$ & 0.84 & 1.83 & 0.12 & -0.21 & 0.22 \\
\hline & Q & 0.13 & 0.52 & 0.05 & -0.10 & 0.05 \\
\hline \multirow{2}{*}{12} & $Z$ & -1.40 & 0.63 & -1.45 & -0.31 & -0.82 \\
\hline & Q & -0.24 & 0.21 & -0.62 & -0.09 & -0.17 \\
\hline \multirow{2}{*}{13} & $Z$ & -0.90 & 0.81 & -0.90 & -0.11 & -0.30 \\
\hline & Q & -0.13 & 0.27 & -0.39 & -0.03 & -0.10 \\
\hline \multirow{2}{*}{14} & $Z$ & -0.76 & 0.86 & -0.95 & -0.28 & -0.22 \\
\hline & Q & -0.11 & 0.32 & -0.38 & -0.12 & -0.03 \\
\hline \multirow{2}{*}{15} & $Z$ & -1.89 & 0.25 & -1.64 & -0.60 & -0.17 \\
\hline & Q & -0.30 & 0.08 & -0.65 & -0.23 & -0.05 \\
\hline
\end{tabular}

$\mathrm{Q}$ is in $\mathrm{mm} /$ year.

prediction and to determine its magnitude, while Sequential Mann Kendall approach was used for the detection of beginning of trend, trend change, and abrupt change of it. In order to remove the correlation effect from data, prewhitening of data was performed. Overall watershed trends in the study area were also determined. It was found that precipitation had insignificant positive trend at most parts of the watershed during 1901-2013 for annual and seasonal data series. 1960 is the change year for precipitation data series being observed by applying Sequential Mann Kendall method. It was found that precipitation results of the first (1901-1960) and second (1961-2013) data series have a mixture of insignificant positive and negative trends at most of the stations in the seasonal and annual data series. In general, stations for winter, summer, and autumn seasons exhibit positive precipitation trend for both data series, while spring exhibits negative insignificant trend. The results of TMax for time series show a significant positive trend at $1 \%$ and $5 \%$ significance level
TABLE 4: Mann Kendall and TSA results of precipitation during the period of 1961-2013.

\begin{tabular}{|c|c|c|c|c|c|c|}
\hline Stations & & Annual & Winter & Spring & Summer & Autumn \\
\hline \multirow{2}{*}{1} & $Z$ & -1.43 & -0.91 & -1.45 & -0.44 & 1.590 \\
\hline & Q & -0.17 & -0.17 & -0.57 & -0.11 & 0.34 \\
\hline \multirow{2}{*}{2} & $Z$ & -0.98 & -0.24 & -1.16 & 0.02 & 1.803 \\
\hline & Q & -0.19 & -0.06 & -0.48 & 0.00 & 0.32 \\
\hline \multirow{2}{*}{3} & $Z$ & -1.22 & -0.43 & -1.33 & -0.28 & 1.750 \\
\hline & Q & -0.20 & -0.10 & -0.55 & -0.08 & 0.33 \\
\hline \multirow{2}{*}{4} & $Z$ & -0.80 & 0.59 & -1.89 & 0.07 & 1.47 \\
\hline & Q & -0.14 & 0.13 & -0.80 & 0.01 & 0.24 \\
\hline \multirow{2}{*}{5} & $Z$ & -0.14 & 0.08 & -0.60 & 0.05 & 0.222 \\
\hline & Q & -0.14 & 0.08 & -0.60 & 0.05 & 0.22 \\
\hline \multirow{2}{*}{6} & $Z$ & -0.96 & 0.19 & -1.25 & 0.25 & 1.186 \\
\hline & $Q$ & -0.16 & 0.03 & -0.57 & 0.09 & 0.23 \\
\hline \multirow{2}{*}{7} & $Z$ & -1.16 & -0.21 & -1.55 & 0.05 & 1.684 \\
\hline & $Q$ & -0.18 & -0.04 & -0.50 & 0.02 & 0.28 \\
\hline \multirow{2}{*}{8} & $Z$ & -0.48 & 0.59 & -1.46 & 0.72 & 0.842 \\
\hline & Q & -0.08 & 0.15 & -0.57 & 0.21 & 0.14 \\
\hline \multirow{2}{*}{9} & $Z$ & -0.64 & 0.52 & -1.74 & 0.59 & 0.753 \\
\hline & Q & -0.12 & 0.11 & -0.54 & 0.18 & 0.11 \\
\hline \multirow{2}{*}{10} & $Z$ & -1.19 & 0.15 & -1.96 & 0.55 & 0.931 \\
\hline & $Q$ & -0.16 & 0.02 & -0.47 & 0.17 & 0.16 \\
\hline \multirow{2}{*}{11} & $Z$ & -1.20 & 0.11 & -1.80 & 0.18 & 1.601 \\
\hline & Q & -0.15 & 0.03 & -0.51 & 0.08 & 0.24 \\
\hline \multirow{2}{*}{12} & $Z$ & -0.75 & 0.11 & -1.91 & 1.30 & -0.214 \\
\hline & Q & -0.11 & 0.02 & -0.61 & 0.34 & -0.04 \\
\hline \multirow{2}{*}{13} & $Z$ & -0.89 & 0.24 & -1.89 & 1.23 & -0.113 \\
\hline & $Q$ & -0.13 & 0.05 & -0.58 & 0.35 & -0.01 \\
\hline \multirow{2}{*}{14} & $Z$ & -0.74 & 0.53 & -1.90 & 1.15 & 0.225 \\
\hline & $Q$ & -0.08 & 0.07 & -0.49 & 0.30 & 0.04 \\
\hline \multirow{2}{*}{15} & $Z$ & -0.28 & 0.31 & -1.59 & 1.73 & -0.540 \\
\hline & Q & -0.03 & 0.03 & -0.47 & 0.50 & -0.08 \\
\hline
\end{tabular}

$\mathrm{Q}$ is in $\mathrm{mm} /$ year.

for annual and seasonal data series during 1901-2013 period. TSA magnitude shows that TMax is increasing between 0.09 and $0.29^{\circ} \mathrm{C} / \mathrm{decade}$, while TMin increases annually and in summer during the 1901-2013 period, at the rate of 0.14$0.22^{\circ} \mathrm{C} /$ decade. At the majority of stations, seasonal data series exhibit an increase up to $0.22^{\circ} \mathrm{C} /$ decade.

Precipitation trend was found insignificant at a regional basis for annual and seasonal data series. TMax and TMin have significant trends at $1 \%$ and $5 \%$ significance level for time series over the whole study region.

This paper draws the picture of maximum and minimum temperature and precipitation trends during the last 113 years, which is helpful for future water resource planning, application, management and distribution for agriculture, and commercial, domestic, and other usages. This study can be beneficial to predict the future trend of maximum and minimum temperatures and also of precipitation. Various techniques could be beneficial for trend prediction within 
TABLE 5: The percentage of the grid points having significant trends by TSA of annual and seasonal data.

\begin{tabular}{|c|c|c|c|c|c|c|c|}
\hline Grid variable & Trend & $\alpha$ & Annual & Winter & Spring & Summer & Autumn \\
\hline \multicolumn{8}{|l|}{ Precipitation } \\
\hline \multirow{4}{*}{ 1901-1960 } & \multirow{2}{*}{ Positive } & 0.05 & 20 & 13.33 & 6.66 & - & - \\
\hline & & $\leq 0.01$ & - & 13.33 & - & - & - \\
\hline & \multirow{2}{*}{ Negative } & 0.05 & - & - & 100 & - & - \\
\hline & & $\leq 0.01$ & - & - & - & - & - \\
\hline \multirow{4}{*}{ 1961-2013 } & \multirow{2}{*}{ Positive } & 0.05 & - & - & - & - & - \\
\hline & & $\leq 0.01$ & - & - & - & - & - \\
\hline & \multirow{2}{*}{ Negative } & 0.05 & - & - & - & - & - \\
\hline & & $\leq 0.01$ & - & - & - & - & - \\
\hline \multicolumn{8}{|l|}{ TMax } \\
\hline \multirow{4}{*}{ 1901-2013 } & \multirow{2}{*}{ Positive } & 0.05 & - & 46.67 & - & - & 13.33 \\
\hline & & $\leq 0.01$ & 100 & 53.33 & 100 & 100 & 86.67 \\
\hline & \multirow{2}{*}{ Negative } & 0.05 & - & - & - & - & - \\
\hline & & $\leq 0.01$ & - & - & - & - & - \\
\hline \multicolumn{8}{|l|}{ TMin } \\
\hline \multirow{4}{*}{ 1901-2013 } & \multirow{2}{*}{ Positive } & 0.05 & 93.33 & - & 20 & - & - \\
\hline & & $\leq 0.01$ & - & - & 80 & 100 & \\
\hline & \multirow{2}{*}{ Negative } & 0.05 & - & - & - & - & - \\
\hline & & $\leq 0.01$ & - & - & - & - & - \\
\hline
\end{tabular}

$(-)$ means no trend.

TABLE 6: Statistical results of the average precipitation and temperature data related to the whole study area.

\begin{tabular}{lcccccccc}
\hline & \multicolumn{4}{c}{ Precipitation } & \multicolumn{2}{c}{ TMax (1901-2013) } & \multicolumn{2}{c}{ TMin (1901-2013) } \\
Seasons/time series & \multicolumn{2}{c}{ First data series (1901-1960) } & Second data series (1961-2013) & $Z$ & TSA $\left({ }^{\circ} \mathrm{C} /\right.$ year) & $Z$ & TSA $\left({ }^{\circ} \mathrm{C} /\right.$ year) \\
& $Z$ & TSA (mm/year) & $Z$ & TSA (mm/year) & & & \\
\hline Annual & 0.75 & 0.158 & -1.07 & -0.156 & 4.20 & 0.033 & 3.68 \\
Winter & 1.67 & 0.585 & 0.09 & 0.010 & 2.64 & 0.028 & 1.82 & 0.016 \\
Spring & 0.42 & 0.135 & -1.81 & -0.554 & 3.96 & 0.034 & 3.22 & 0.013 \\
Summer & 0.17 & 0.067 & 0.43 & 0.104 & 4.20 & 0.044 & 3.41 & 0.022 \\
Autumn & -0.07 & -0.019 & 1.00 & 0.166 & 2.74 & 0.024 & 1.62 & 0.015 \\
\hline
\end{tabular}

the study area and for determining the validity of presented methods in this study.

\section{Conflict of Interests}

The authors declare that there is no conflict of interests regarding the publication of this paper.

\section{Acknowledgments}

The authors thank the editor of this paper and reviewers for their positive and encouraging comments for the polishing this paper.

\section{References}

[1] C.-Y. Xu and V. P. Singh, "Review on regional water resources assessment models under stationary and changing climate," Water Resources Management, vol. 18, no. 6, pp. 591-612, 2004.

[2] S. W. Kienzle, M. W. Nemeth, J. M. Byrne, and R. J. MacDonald, "Simulating the hydrological impacts of climate change in the upper North Saskatchewan River basin, Alberta, Canada," Journal of Hydrology, vol. 412-413, pp. 76-89, 2012.

[3] A. C. Costa and A. Soares, "Homogenization of climate data: review and new perspectives using geostatistics," Mathematical Geosciences, vol. 41, no. 3, pp. 291-305, 2009.

[4] Intergovernmental Panel on Climate Change (IPCC), The Data distribution center, DDC, 2001, http://ipcc-ddc.cru.uea.ac.uk/.

[5] S. Trajkovic and S. Kolakovic, "Wind-adjusted Turc equation for estimating reference evapotranspiration at humid European locations," Hydrology Research, vol. 40, no. 1, pp. 45-52, 2009.

[6] P. Campling, A. Gobin, and J. Feyen, “Temporal and spatial rainfall analysis across a humid tropical catchment," Hydrological Processes, vol. 15, no. 3, pp. 359-375, 2001.

[7] Z. X. Xu, K. Takeuchi, H. Ishidaira, and J. Y. Li, "Long-term trend analysis for precipitation in Asian Pacific FRIEND river basins," Hydrological Processes, vol. 19, no. 18, pp. 3517-3532, 2005.

[8] IPCC, Climate Change 2007: The Physical Science Basis, Contribution of Working Group I to the Fourth Assessment Report of the Intergovernmental Panel of Climate Change, Cambridge University Press, Cambridge, UK, 2007. 
[9] IPCC, Climate Change 2013: The Physical Science Basis, Contribution of Working Group I to the Fifth Assessment Report of the Intergovernmental Panel of Climate Change, Cambridge University Press, Cambridge, UK, 2013.

[10] R. S. Maragatham, "Trend analysis of rainfall data: a comparative study of existing methods," International Journal of Physics and Mathematical Sciences, vol. 2, pp. 13-18, 2011.

[11] P. C. D. Milly, K. A. Dunne, and A. V. Vecchia, "Global pattern of trends in streamflow and water availability in a changing climate," Nature, vol. 438, no. 7066, pp. 347-350, 2005.

[12] D. Y. Qin Dahe, Assessment on Environment Change in Eastern China, Science Publishing House, Beijing, China, 2002.

[13] Y. Gu, J. Lin, X.-L. Wang, and X.-J. Zhang, "Trend of annual runoff for major rivers in China under climate change," Procedia Engineering, vol. 28, pp. 564-568, 2012.

[14] Y. He and Y. Zhang, "Climate change from 1960 to 2000 in the Lancang River valley, China," Mountain Research and Development, vol. 25, no. 4, pp. 341-348, 2005.

[15] P. Sonali and D. N. Kumar, "Review of trend detection methods and their application to detect temperature changes in India," Journal of Hydrology, vol. 476, pp. 212-227, 2013.

[16] H. B. Mann, "Nonparametric tests against trend," The Econometric Society, vol. 13, no. 3, pp. 245-259, 1945.

[17] M. G. Kendall, Rank Correlation Measures, Charles Griffin, London, UK, 1975.

[18] H. A. Theil, "A rank-invariant method of linear and polynomial regression analysis," Proceedings of the Koninklijke Nederlandse Akademie Van Wetenschappen Series A, vol. 53, pp. 386-392, 1950.

[19] P. K. Sen, "Estimates of the regression coefficient based on Kendall's tau," Journal of the American Statistical Association, vol. 63, no. 324, pp. 1379-1389, 1968.

[20] D. Nalley, J. Adamowski, B. Khalil, and B. Ozga-Zielinski, "Trend detection in surface air temperature in Ontario and Quebec, Canada during 1967-2006 using the discrete wavelet transform," Atmospheric Research, vol. 132-133, pp. 375-398, 2013.

[21] A. Karaburun, A. Demirci, and F. Kara, "Analysis of spatially distributed annual, seasonal and monthly temperatures in Istanbul from 1975 to 2006," World Applied Sciences Journal, vol. 12, no. 10, pp. 1662-1675, 2011.

[22] P. Ceppi, S. C. Scherrer, A. M. Fischer, and C. Appenzeller, "Revisiting Swiss temperature trends 1959-2008," International Journal of Climatology, vol. 32, no. 2, pp. 203-213, 2012.

[23] X.-H. Fan and M.-B. Wang, "Change trends of air temperature and precipitation over Shanxi Province, China," Theoretical and Applied Climatology, vol. 103, no. 3-4, pp. 519-531, 2011.

[24] H. Tao, M. Gemmer, Y. Bai, B. Su, and W. Mao, "Trends of streamflow in the Tarim River Basin during the past 50 years: human impact or climate change?" Journal of Hydrology, vol. 400, no. 1-2, pp. 1-9, 2011.

[25] Y. Jiang, Y. Luo, Z. Zhao, and S. Tao, "Changes in wind speed over China during 1956-2004," Theoretical and Applied Climatology, vol. 99, no. 3-4, pp. 421-430, 2010.

[26] P. Singh, V. Kumar, T. Thomas, and M. Arora, "Changes in rainfall and relative humidity in river basins in northwest and central India," Hydrological Processes, vol. 22, no. 16, pp. 29822992, 2008.

[27] M. N. ElNesr, M. M. Abu-Zreig, and A. A. Alazba, "Temperature trends and distribution in the Arabian peninsula," American Journal of Environmental Sciences, vol. 6, pp. 191-203, 2010.
[28] T. Partal and E. Kahya, "Trend analysis in Turkish precipitation data," Hydrological Processes, vol. 20, no. 9, pp. 2011-2026, 2006.

[29] B. S. Some'e, A. Ezani, and H. Tabari, "Spatiotemporal trends and change point of precipitation in Iran," Atmospheric Research, vol. 113, pp. 1-12, 2012.

[30] S. Chatterjee, D. Bisai, and A. Khan, "Detection of approximate potential trend turning points in temperature time series (19412010) for Asansol weather observation station, West Bengal, India," India. Atmospheric and Climate Sciences, vol. 4, pp. 6469, 2014.

[31] M. New, M. Hulme, and P. Jones, "Representing twentiethcentury space-time climate variability. Part II: development of 1901-96 monthly grids of terrestrial surface climate," Journal of Climate, vol. 13, no. 13, pp. 2217-2238, 2000.

[32] I. Harris, P. D. Jones, T. J. Osborn, and D. H. Lister, "Updated high-resolution grids of monthly climatic observations-the CRU TS3.10 dataset," International Journal of Climatology, vol. 34, no. 3, pp. 623-642, 2014.

[33] M. Almazroui, M. N. Islam, P. D. Jones, H. Athar, and M. A. Rahman, "Recent climate change in the Arabian Peninsula: seasonal rainfall and temperature climatology of Saudi Arabia for 1979-2009," Atmospheric Research, vol. 111, pp. 29-45, 2012.

[34] M. Tanarhte, P. Hadjinicolaou, and J. Lelieveld, "Intercomparison of temperature and precipitation data sets based on observations in the Mediterranean and the Middle East," Journal of Geophysical Research: Atmospheres, vol. 117, no. 12, Article ID D12102, 2012.

[35] H. Von Storch and A. Navarra, Analysis of Climate VariabilityApplications of Statistical Techniques, Springer, New York, NY, USA, 1995.

[36] J. D. Salas, J. W. Delleur, V. Yevjevich, and W. L. Lane, Applied Modelling of Hydrologic Time Series, Water Resources Publications, Littleton, Colo, USA, 1980.

[37] M. Gocic and S. Trajkovic, "Analysis of changes in meteorological variables using Mann-Kendall and Sen's slope estimator statistical tests in Serbia," Global and Planetary Change, vol. 100, pp. 172-182, 2013.

[38] H. Tabari and P. H. Talaee, "Analysis of trends in temperature data in arid and semi-arid regions of Iran," Global and Planetary Change, vol. 79, no. 1-2, pp. 1-10, 2011.

[39] F.-W. Gerstengarbe and P. C. Werner, "Estimation of the beginning and end of recurrent events within a climate regime," Climate Research, vol. 11, no. 2, pp. 97-107, 1999.

[40] Y. Song, C. Achberger, and H. W. Linderholm, "Rain-season trends in precipitation and their effect in different climate regions of China during 1961-2008," Environmental Research Letters, vol. 6, no. 3, Article ID 034025, 2011.

[41] Y. Tian, Y.-P. Xu, M. J. Booij, S. Lin, Q. Zhang, and Z. Lou, "Detection of trends in precipitation extremes in Zhejiang, East China," Theoretical and Applied Climatology, vol. 107, no. 1-2, pp. 201-210, 2012.

[42] Y. Wang and L. Zhou, "Observed trends in extreme precipitation events in China during 1961-2001 and the associated changes in large-scale circulation," Geophysical Research Letters, vol. 32, no. 9, Article ID L09707, 2005.

[43] P. Zhao, P. Jones, L. Cao et al., "Trend of surface air temperature in Eastern China and associated large-scale climate variability over the last 100 years," Journal of Climate, vol. 27, no. 12, pp. 4693-4703, 2014.

[44] D. Dong, G. Huang, X. Qu, W. Tao, and G. Fan, “Temperature trend-altitude relationship in China during 1963-2012," Theoretical and Applied Climatology, vol. 4, pp. 64-69, 2014. 
[45] G. Tang, Y. Ding, S. Wang, G. Ren, H. Liu, and L. Zhang, "Comparative analysis of China surface air temperature series for the past 100 years," Advances in Climate Change Research, vol. 1, no. 1, pp. 11-19, 2010.

[46] S. Piao, P. Ciais, Y. Huang et al., "The impacts of climate change on water resources and agriculture in China," Nature, vol. 467, no. 7311, pp. 43-51, 2010. 

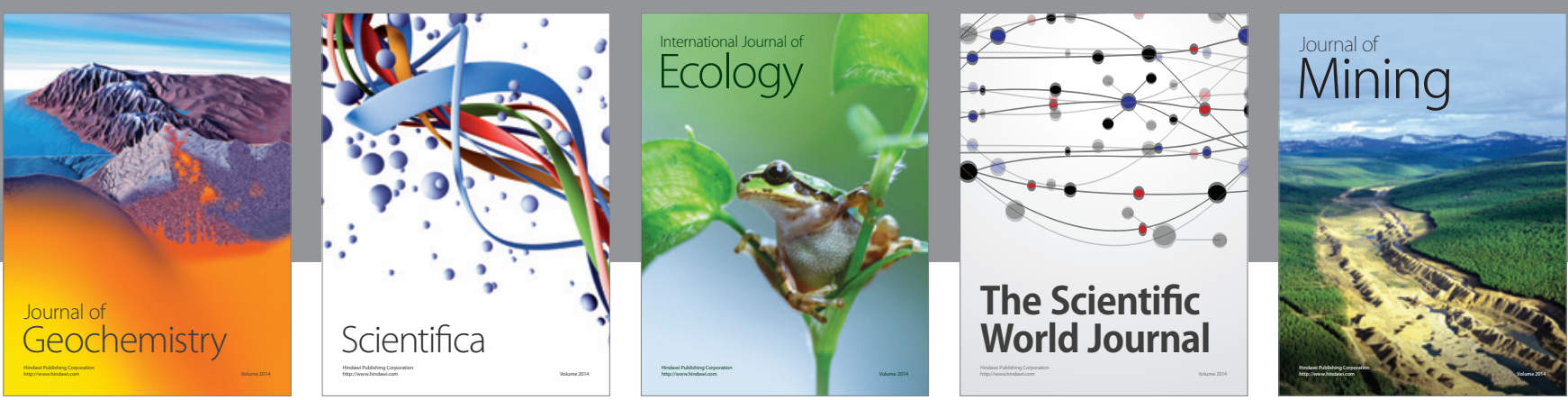

The Scientific World Journal
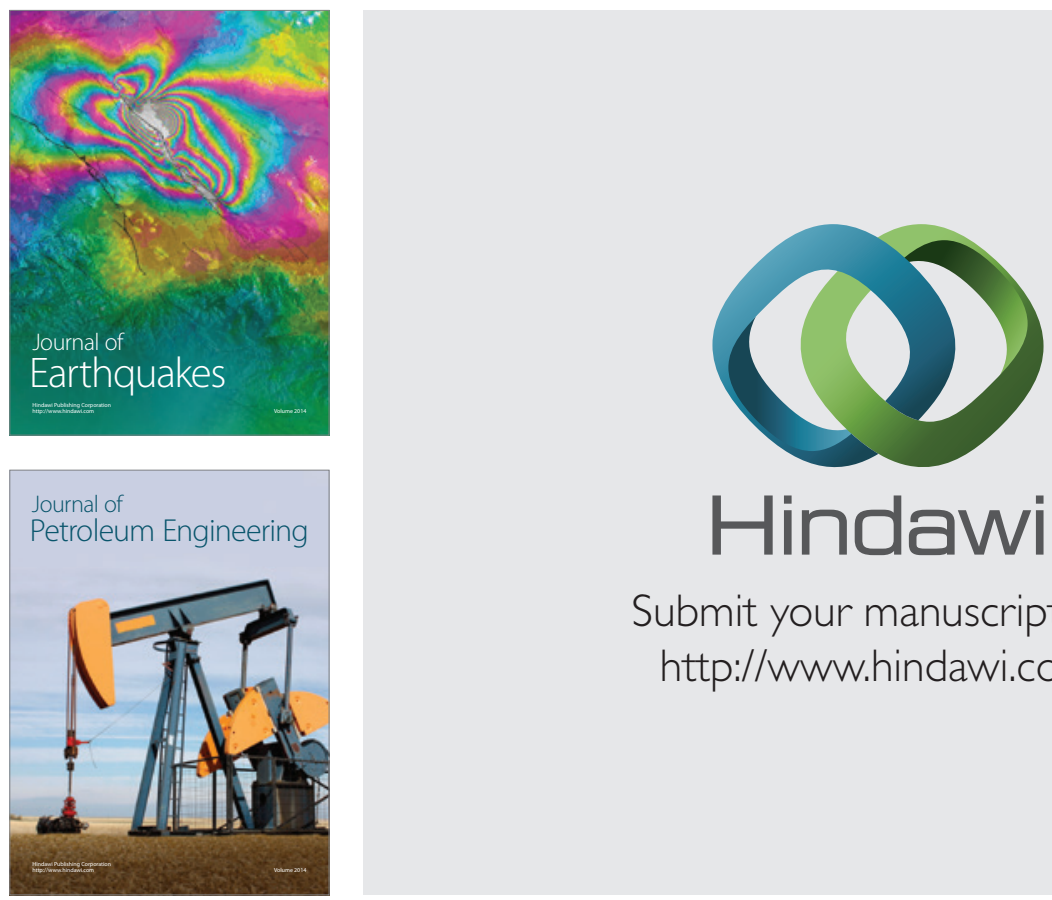

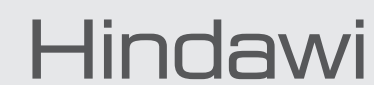

Submit your manuscripts at

http://www.hindawi.com
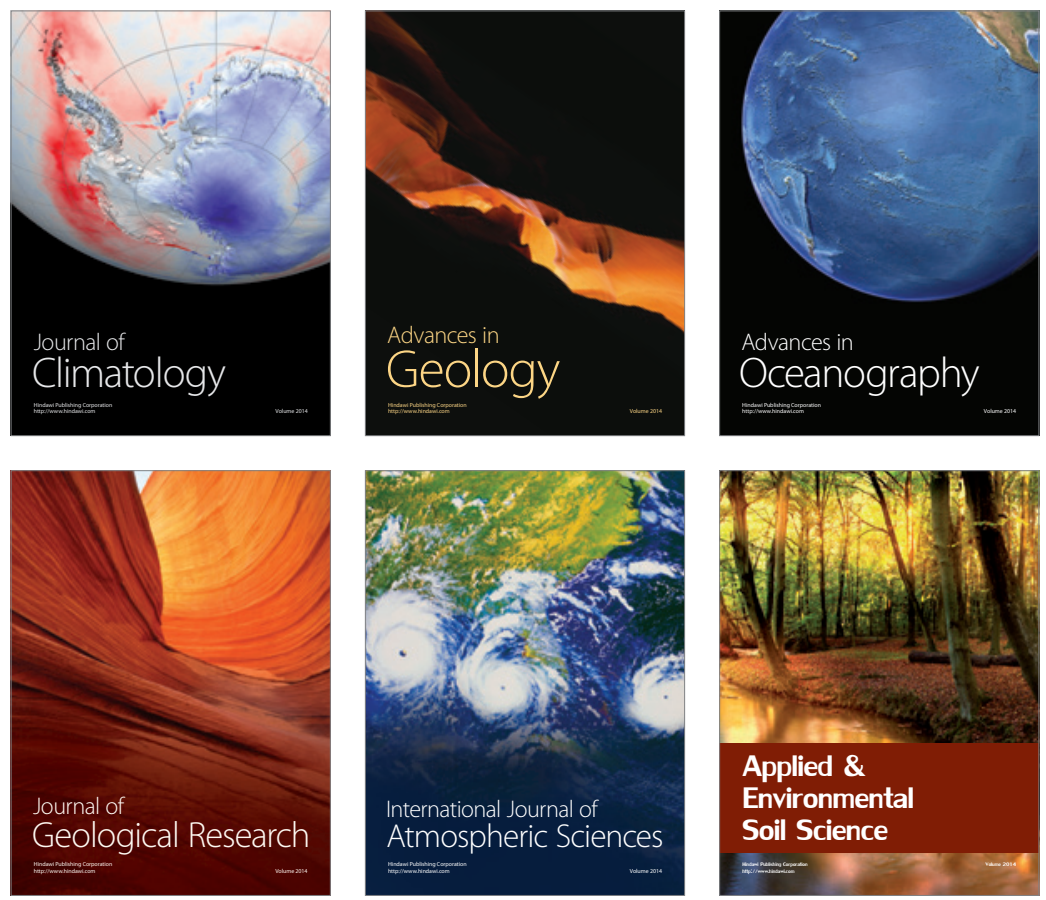
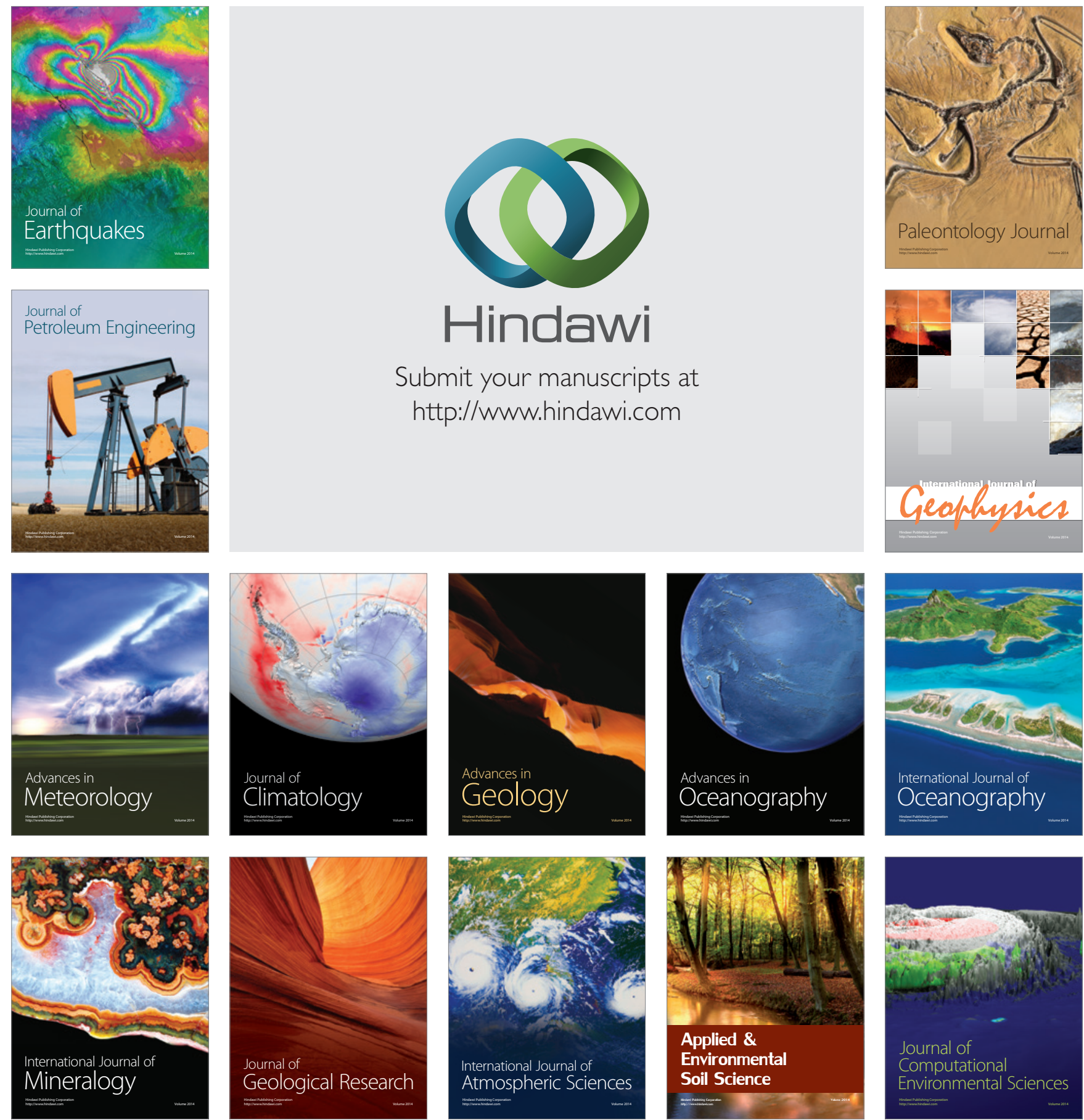